\title{
Study on Safety Coefficient and Failure Face Ratio of Slope with Soft Layer
}

\author{
Ming-hui Gao ${ }^{1}$, Jian-qing Zhao ${ }^{1}$, Chao Sun $^{1}$, Xiao Wang ${ }^{2 *}$ and Qi-zhi Wang ${ }^{2}$ \\ ${ }^{1}$ Hebei Key Laboratory of Geological Resources and Environment Monitoring and Protection, 050021 Shijiazhuang, China \\ ${ }^{2}$ Hebei University of Science and Technology, 050018 Shijiazhuang, China
}

\begin{abstract}
In this paper, the slope with horizontal weak interlayer is taken as the research object, and the safety factor and the location of the failure surface of the slope are calculated by finite element strength reduction method and limit equilibrium method respectively. The results show that when the slope is mixed with soft layer, the positions of the critical failure surfaces calculated by the two methods are quite different, but their safety factors are relatively small. Which method is more accurate needs to be analyzed in combination with the specific conditions of the slope. Through comparative analysis, the calculation efficiency of limit equilibrium method is much higher than that of strength reduction method. The results of this paper provide reliable reference for engineering analysis.
\end{abstract}

\section{Introduction}

Limit equilibrium method is widely used in engineering and academic circles to analyze slope stability. Although the limit equilibrium method does not consider the stress-strain relationship of soil, it can still give the slope safety factor without knowing the initial conditions, so it is favored by engineers. As we all know, the limit equilibrium method is a statically indeterminate problem. In order to solve the safety factor, it is necessary to assume the internal force of the slip surface. The method proposed by Baker and Garber ${ }^{[1]}$ does not need to assume the distribution of internal forces, but it is rather complicated. Morgenstern ${ }^{[2]}$ pointed out that for general problems, the results of different assumptions are basically similar, so there is no need to assume complicated internal force distribution when there is no special requirement. Cheng ${ }^{[3]}$ discussed many critical failure interface methods in detail. Although these schemes can solve most problems, there may be difficulties in solving local minima. Cheng et al. ${ }^{[4]}$ adopt an improved simulated annealing method which is one of the few methods that can solve the local minimum. Zienkiewicz et al. ${ }^{[5]}$ used strength reduction method to analyze slope stability. Subsequently, many researchers conducted research and applied $\mathrm{it}^{[6-10]}$. This technology has been adopted by many famous geotechnical finite element programs. The points of strength and subtraction lie in [11]: (i) the critical failure surface is automatically calculated by the shear strain caused by the application of gravity load and the reduction of shear strength; (ii) It is not necessary to assume the distribution of interlaminar shear force; (iii) It is suitable for many complex conditions and can provide information such as stress, movement and pore pressure.

Many researchers have compared the strength reduction method with the limit equilibrium method, and found that the results of the two methods are very close when analyzing the safety of the mean slope, that is, when there is no thin weak interlayer. However, most studies are limited to homogeneous soil slopes, and the geometry of the problem is regular without other special features, such as no inclusion of weak thin layers. In previous studies, slope safety factor is the main research object, but the comparison of critical failure interface positions between the two is relatively rare. This paper compares the two methods under different conditions, and studies whether the safety factor is consistent with the position of the critical failure surface.

\section{Slope stability analysis theory}

Strength reduction method is widely used in slope stability analysis. Firstly, the initial reduction factor is selected, the strength parameters of rock and soil are reduced, and the reduced parameters are taken as input for finite element calculation. If the program converges, the rock and soil are still in a stable state, and then the reduction factor is increased until the program just does not converge, and the reduction factor at this time is the stable safety factor. 
Strength parameter reduction is carried out according to the following formula ${ }^{[12]}$ :

$$
\begin{gathered}
c_{\mathrm{e}}=c / F \\
\tan \varphi e^{=\tan \varphi / \mathrm{F}} \\
\varphi_{\mathrm{e}}=\arctan (\tan \varphi / \mathrm{F})
\end{gathered}
$$

Where, $\mathrm{c}$ is cohesion; $\varphi$ Internal friction angle; $\mathrm{F}$ is the reduction factor; $\mathrm{C}_{\mathrm{e}}, \varphi_{e}$ is a new set of cohesion and internal friction angle.

Physical significance of safety factor: The finite element strength reduction factor method has the same physical significance as the safety factor defined by Bishop.

$$
F_{S}=\frac{\tau_{f(\text { average })}}{\tau_{(\text {average })}}
$$

$$
\begin{aligned}
& \text { Or } F_{\mathrm{s}}=\int_{i}(\sigma \tan \varphi+c) \mathrm{d} l / \int_{i} \tau \mathrm{d} l \\
& \text { Or } F_{s}=\int_{i} \tau_{\mathrm{f}} \mathrm{d} l / \int_{i} \tau \mathrm{d} l
\end{aligned}
$$

Where, $\tau$ is the shear stress along the sliding surface, $\tau_{f}$

is the shear strength at this point, $d l$ is the length of the sliding surface microelement, and $\boldsymbol{F s}$ is the strength reduction factor.

Determination of the location of the slip surface: after the strength coefficient of the soil slope is reduced, a plastic zone will appear in the soil slope by nonlinear finite element analysis. the equivalent diagram of plastic strain is shown in fig. 1 . When the soil slides, the plastic strain value near the shear plane is larger than that at both sides, so the slip plane must pass through the peak point of the maximum plastic strain. The dotted line in the figure is the line through the ridge of isoline, which is the most dangerous sliding surface.

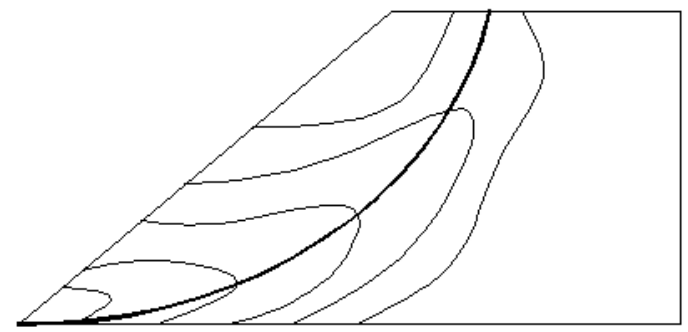

Fig. 1 determine that most likely slip surface

\section{Stability Analysis of Heterogeneous Soil Slope}

In this paper, a heterogeneous soil slope model with soft soil layers is constructed, and similar problems are rarely considered in previous studies. The size of the model is shown in Figure 2, and the soil parameters of the model are shown in Table 1. It is worth noting that the cohesion
$\mathrm{C}$ of the second layer of soil is 0 , and the critical failure surface of the soil is obviously controlled by the soft soil interlayer, and this situation exists in practical engineering. Regardless of the size effect (boundary effect), the yield criterion adopts the Mohr-Coulomb criterion, and the strength reduction method is used to analyze this. Assuming that the mesh division is fine

\begin{tabular}{|c|c|c|c|c|c|}
\hline $\begin{array}{c}\text { Numb } \\
\text { er }\end{array}$ & $\begin{array}{c}\text { elastic } \\
\text { modulus/M } \\
\mathrm{Pa}^{2}\end{array}$ & $\begin{array}{l}\text { Poisson } \\
\text { 's ratio }\end{array}$ & $\begin{array}{c}\text { densi } \\
\text { ty } \\
\mathrm{kg} / \mathrm{m}^{3}\end{array}$ & $\begin{array}{c}\text { frictio } \\
\mathbf{n} \\
\text { angle } \\
\left({ }^{\circ}\right)\end{array}$ & $\begin{array}{c}\text { Cohesi } \\
\text { ve } \\
\text { force } \\
\text { (kPa) }\end{array}$ \\
\hline 1 & \multirow{3}{*}{14} & \multirow{3}{*}{0.3} & \multirow{3}{*}{1900} & 35 & 20 \\
\hline 2 & & & & 25 & 0 \\
\hline 3 & & & & 35 & 10 \\
\hline
\end{tabular}
enough and has no influence on the result, the model adopts 4000 quadrilateral meshes.

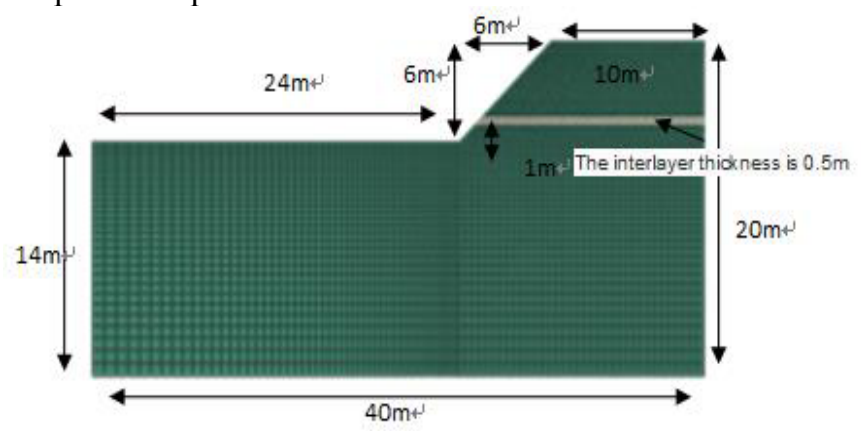

Fig. 2 stability model of heterogeneous soil slope

Table 1 Calculation Parameters

The strength reduction method and Bishop method of non-associated flow law are respectively used for calculation. The safety factor of strength reduction method is 1.88 , Bishop method is 1.84 , and Morgenstern method is 1.78 . Their critical failure surface results are as follows.

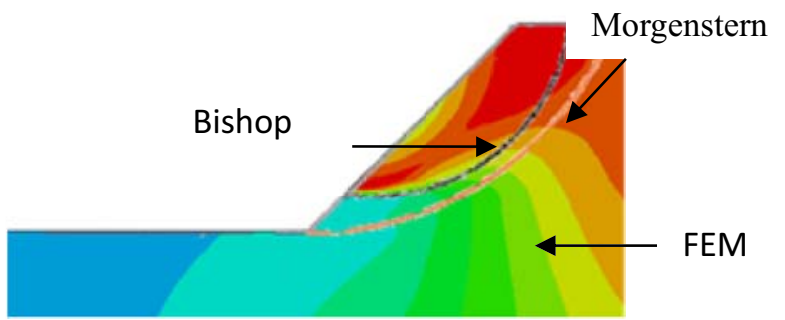

Fig. 3 Critical Failure Face Ratio of Heterogeneous Soil Slope

In fig. 3, the black solid arc is the bishop method result, the cloud image is the intensity reduction subtraction result, and the orange solid arc is the morganstein method result. The position of the critical failure surface of the strength reduction method is basically the same as that of Bishop method. Most of the critical failure surfaces are located in the second layer, which has low shear strength and is far from the right boundary. However, the critical failure surface of Morgenstern method is different from other methods, and the range of failure surface is also larger.

From the above results, it can be seen that the limit equilibrium method needs to be very careful in calculating the slope safety factor. It is sensitive to heterogeneous slope with weak interlayer, which makes 
it not possible to obtain a completely accurate critical failure surface. As far as the results of this paper are concerned, when there is weak interlayer in the slope, the safety factor calculated by strength reduction is basically consistent with the traditional limit equilibrium method. There are some differences between the two results when solving the critical failure surface position.

\section{Conclusion}

In this study, some laws of slope stability analysis by strength reduction method and limit equilibrium method are found, which is of great significance to correctly use strength reduction method to analyze slope safety factor. Although most studies focus on the safety factor between strength reduction method and limit equilibrium method, this paper also studies the critical failure surface positions of the two methods. When the slope is mixed with weak layers, the positions of the critical failure surfaces calculated by strength reduction method and limit equilibrium method are quite different. In this case, the limit equilibrium method should carefully refer to the location of the failure surface. For which method is more accurate, it should be analyzed in combination with the specific conditions of the slope.

When strength reduction method is used, it should also be noted that when cohesion and friction angle are small, strength reduction method will have non-convergence problem. In this case, the critical failure surface is a relatively deep and large area, and the solution time is very long. However, it is not difficult to analyze the safety factor and critical failure surface of the problem by using the limit equilibrium method.

Through analysis and comparison, the strength reduction method has the advantage that the critical failure surface does not need to be defined, and the failure surface can be directly produced by post-processing calculation. The limit equilibrium method is limited by the need to assume shear forces between layers, but the computational efficiency is much higher than that of the strength reduction method. However, engineers should be aware of the limitations of each method when evaluating the results, otherwise it is difficult to use reasonable methods to effectively analyze the slope engineering.

\section{Acknowledgements}

This work has been supported by the Natural Science Foundation of Hebei Province of China (Youth Program) under Grants \#E2020208071 and the Natural Science Foundation of Hebei Province of China (Grants \# E2019208159).

\section{References}

1. BAKER R, GARBER M. Theoretical analysis of the stability of slopes [J]. Géotechnique,(1978), 28(4): 395-411.

2. MORGENSTERN N R. The evaluation of slope stability: A 25 year perspective. in [J]. Chemistry, (2010) , 10(13): 3241-51.

3. CHENG Y M. Location of critical failure surface and some further studies on slope stability analysis [J]. Computers and Geotechnics, (2003), 30(3): 255-67.

4. CHENG Y M, LANSIVAARA T, WEI W B. Two-dimensional slope stability analysis by limit equilibrium and strength reduction methods $[\mathrm{J}]$. Computers and Geotechnics,(2007), 34(3): 137-50.

5. C. ZIENKIEWICZ O, HUMPHESON C, LEWIS R Associated and non-associated visco-plasticity and plasticity in soil mechanics [M].(1975).

6. NAYLOR D J. Finite Elements and Slope Stability [M].(1982).

7. DONALD I, GIAM S. Application of the Nodal Displacement Method to Slope Stability Analysis; proceedings of the Australia-new Zealand Conference on Geomechanics: Prediction Versus Performance; Preprints of Papers, F, (1988 )[C].

8. MATSUI T, SAN K-C. Finite element slope stability analysis by shear strength reduction technique [M]. (1992).

9. DAWSON E, MOTAMED F, NESARAJAH S, et al. Geotechnical Stability Analysis by Strength Reduction [M]. (2000).

10. ZHENG Y R, ZHAO S Y, KONG W X, et al. Geotechnical engineering limit analysis using finite element method [M].(2005). 